\title{
Kin Against Kin: Internal Co-selection and the Coherence of Kinship Typologies
}

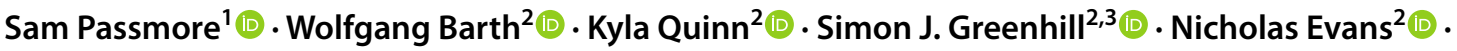 \\ Fiona M. Jordan ${ }^{1}[\mathbb{C}$
}

Received: 4 December 2020 / Accepted: 12 April 2021 / Published online: 7 June 2021

(c) The Author(s) 2021

\begin{abstract}
Across the world people in different societies structure their family relationships in many different ways. These relationships become encoded in their languages as kinship terminology, a word set that maps variably onto a vast genealogical grid of kinship categories, each of which could in principle vary independently. But the observed diversity of kinship terminology is considerably smaller than the enormous theoretical design space. For the past century anthropologists have captured this variation in typological schemes with only a small number of model system types. Whether those types exhibit the internal co-selection of parts implicit in their use is an outstanding question, as is the sufficiency of typologies in capturing variation as a whole. We interrogate the coherence of classic kinship typologies using modern statistical approaches and systematic data from a new database, Kinbank. We first survey the canonical types and their assumed patterns of internal and external co-selection, then present two data-driven approaches to assess internal coherence. Our first analysis reveals that across parents' and ego's (one's own) generation, typology has limited predictive value: knowing the system in one generation does not reliably predict the other. Though we detect limited co-selection between generations, "disharmonic" systems are equally common. Second, we represent structural diversity with a novel multidimensional approach we term kinship space. This approach reveals, for ego's generation, some broad patterning consistent with the canonical typology, but diversity (and mixed systems) is considerably higher than classical typologies suggest. Our results strongly challenge the descriptive adequacy of the set of canonical kinship types.
\end{abstract}

Keywords Anthropology $\cdot$ Cross-cultural kinship $\cdot$ Linguistics $\cdot$ Semantic systems $\cdot$ Typology

\section{Introduction}

In the languages of all societies, the vast number of logically distinguishable kin types (e.g., categories such as father's younger sister, father's older sister, mother's younger sister, mother's older sister) are mapped onto a smaller and more tractable set of kin terms (e.g., aunt for all the above terms

Fiona M. Jordan

fiona.jordan@bristol.ac.uk

1 Department of Anthropology and Archaeology, University of Bristol, Bristol, UK

2 ARC Centre of Excellence for the Dynamics of Language (CoEDL), Australian National University, Canberra, ACT, Australia

3 Department of Linguistic and Cultural Evolution, Max Planck Institute for the Science of Human History, Jena, Germany in English). ${ }^{1}$ The kinship system of any language can thus be seen as a particular matrix of equivalences or "syncretisms" demonstrating which kin types use identical or similar terms, and which are differentiated. The taken-for-granted nature of how we use language means that the conflation of such categories seem obvious to speakers of the language that uses them (here English, for aunt), but counterintuitive to those whose own languages offer different conceptual cuts (e.g., the Australian language Kayardild, which would reserve the term marrkathu for father's sisters but group mother's sisters with one's mother, as ngamathu (Evans 2011)). Linguists and anthropologists must thus move between the languageinternal conceptual groupings that seem obvious to their speakers (aunt; marrkathu), generally called emic in the literature, and the finer language-independent categories

\footnotetext{
${ }^{1}$ Useful papers surveying this topic are Dole (1969) and Hage (2001).
} 
(e.g., "father's older sister") ${ }^{2}$ which form an etic grid against which language-specific categories can be calibrated. Kin types are etic; kin terms are emic, and the cross-linguistic study of kinship terminology focuses on the different ways languages map their kin terms onto the universally-definable etic grid to produce kinship systems.

Notably, the enormous design space of possible kinship systems is thinly populated amongst vast empty spaces. The pioneering study of sibling terms by Nerlove and Romney (1967) found that among 4,140 possible sibling term systems, ${ }^{3}$ only 15 systems occurred more than twice in their sample of 245 languages, and these 15 occupied $95.5 \%$ of the sample; moreover, there were only 23 systems altogether within their sample. Once we move from sibling terms to parents, uncles and aunts, cousins, grandkin, and in-laws, the number of possible systems rapidly climbs into unimaginably large numbers. ${ }^{4}$ The same pattern holds: there are a strikingly limited number of attested systems with respect to those that are logically possible. Some of these unattested possibilities, it has been argued, are due to trade-offs between simplicity and informativeness (Kemp and Regier 2012; Kemp et al. 2018). These can take the form of markedness constraints, favoring the greater elaboration of terms for nearer rather than more distant kin, or a preference for conjunctive characterizations ("elder AND male referent, i.e., elder brother") over disjunctive ones ("elder OR male referent," i.e., brother (younger or older) or older sister) (Greenberg 1966). However, studies like these only identify some of the constraints on attested systems, and we focus here on a further potential constraint-the consistency of where distinctions or mergers are made-as a selector on why so few systems populate the enormous design space. We will term this internal co-selection since it implies that a design feature of one part of the system (say, the treatment of uncle terms) has selective consequences for another part of the kin system (say, the treatment of cousin terms): there is co-selection, by hypothesis, between different syncretisms within the overall system. Understanding the constraints on these semantic systems of social life, how they emerge and change, and why we see some but not others, has been an

\footnotetext{
${ }^{2}$ For brevity, we use the following abbreviations for the rest of the article: $\mathrm{B}=$ brother, $\mathrm{D}=$ daughter, $\mathrm{e}=$ elder, $\mathrm{f}=$ female referent, $\mathrm{F}=$ father, $\mathrm{G}=$ sibling, $\mathrm{m}=$ male referent, $\mathrm{M}=$ mother, $\mathrm{S}=$ son, $\mathrm{y}=$ younger, $\mathrm{X}=$ cross, $\mathrm{Z}=$ sister, $/ /=$ parallel. These are chained together as appropriate, e.g., MB for "mother's brother."

${ }^{3}$ Nerlove and Romney considered eight possible kin types, defined by the three-way binary matrix "sex of referent" versus "sex of ego" versus "referent older or younger than ego." Some further distinctions are possible but are rare. The figure of 4140 is the Bell number for 8 (the number of ways a set of 8 cells can be partitioned into groups).

4 The authors' database gives terms for 98 kin types (still just a subset of all possible kin terms-it excludes, e.g., great-uncles and greataunts) and the Bell number for these 98 terms is $5.55 \times 10^{112}$.
}

anthropological puzzle for decades. Situated at a nexus of language, cognition, and social reproduction, kinship systems offer a multifaceted domain through which to explore cognitive and cultural evolution.

Since the pioneering work of Morgan (1871) and Fison and Howitt (Gardner and McConvell 2015) in the 19th century, scholars have worked to establish an encompassing typology of kinship systems for the languages of the world. By compiling large sets of terms, across many languages, for hundreds of kin types (over 260 in Morgan's case), these researchers discerned recurrent patterns in which different parts of the system appear to correlate. This led to the classic typologies of the early to mid-20th century (see the "Classic Typologies of Kinship" section), which assigned languages to a canonical "system" (e.g., Iroquois/Dravidian, ${ }^{5}$ Eskimo, ${ }^{6}$ Hawaiian) on the basis of diagnostic syncretisms and distinctions in one crucial subset of the terms (typically siblings and/or parents and nuncles ${ }^{7}$ ). Important questions of external co-selection between particular systems and other social phenomena, could then be pursued empirically: for example, whether the presence of cross-cousin marriage is correlated with Dravidian or Iroquois kinship systems (Godelier et al. 1998). Recurrent and reliably identifiable systems of social and cultural organization make human diversity tractable to cross-cultural analysis, and typologies of (e.g.) subsistence, political organization, and color naming have allowed researchers to ask broad questions about cultural change and statistical regularities. Logically however, the validity of the answers depends on the coherence and operationalizability of the systems themselves, which we can only evaluate once we have good data on how far kin types really do cohere across the whole system of terminology, as well as across a broad and phylogenetically well-balanced sample of languages. While we are certainly not the first to suggest that subsystems will vary independently (e.g., D’Andrade 1971; Murdock 1970), we here advocate a root-and-branch review of these types, capitalizing on new data aggregation and computational methods, with the goal of a more accurate and flexible description of how we carve up the social world.

The aim of this article is the first step in this endeavor: to evaluate whether systems of kinship terminology do in fact exhibit the terminological coherence that the classic typologies presume. We draw on a large global sample of 1,107

\footnotetext{
5 Morgan, whose interest in kinship began with various Iroquoian languages, used the term Iroquois for this type, but subsequent investigators have often used the term Dravidian for what is essentially the same system. See the second section.

${ }^{6}$ We apologize to those Inuit peoples who find this term offensive. We regretfully retain this term here simply because it is the one that articulates with the literature, and we advocate for an alternative.

7 For brevity, we adopt the widespread term "nuncle" for "uncle or aunt" (any sibling of a parent).
} 
languages and $98^{8}$ kin types, enabling us to answer the question of coherence in an empirically grounded way. The size of our dataset allows rare systems to surface and be counted, and we combat sampling issues due to regional or historical autocorrelation by sampling extensively across language families/areas as well as intensively within. The sample also provides key data for explicitly characterizing how internal co-selection actually works, by inviting the consideration of statistical regularities over strict universals. Finally, the synchronic patterning of the kin term "design space" can provide clues as to which elements are linked, and which are not, in their evolution as linguistic and conceptual systems.

We can illustrate the connection between synchronic typology (the set of currently attested states) and internal co-selection in the following way. If the diversity of systems worldwide is restricted as a result of many design elements necessarily co-occurring, then transformations between systems will tend to proceed in bundles of interconnected changes, such as correlated changes in the parental generation and sibling/cousin terms.

Consider the transition from Latin and Old Russian to their descendants Italian and modern Russian. Both exhibit linked changes in the $\mathrm{G}^{+1}$ (parental) and $\mathrm{G}^{0}$ (ego/sibling) generations from a consistent "Sudanese" system in Latin and Old Russian to a consistent "Eskimo" system in Italian and modern Russian ("Sudanese" and "Eskimo" are explained in more detail in the "Classic Typologies of Kinship" section).

Thus, Latin distinguished six main types of $\mathrm{G}^{+1}$ consanguineal kin:

F pater $\neq$ FB patruus $\neq \mathrm{MB}$ avunculus

\section{$\mathrm{M}$ mater $\neq \mathrm{MZ}$ matertera $\neq \mathrm{FZ}$ amita}

and likewise distinguished the children of each of these (except of one's F and M, since these are simply one's siblings), here shown for male kin:

$\mathrm{FS}=\mathrm{MS}$ frater $\neq$ FBS frater patruelis

$\neq$ MBS filius avunculi $\neq$ MZS filius consobrinus $\neq$ FZS amitinus

Its descendant Italian, on the other hand (as for other modern Romance languages descended from Latin), has merged the two uncle terms, and the two aunt terms, but kept them distinct from the parent terms, as in the structurallyidentical English system:

\footnotetext{
8 This is the "basic expanded" figure. The addition of some other less common terms in some languages in our database, such as "born on the same day," "co-wife," etc., expands this figure to 473, but we have less comprehensive cross-linguistic data on this larger set.
}

F padre $\neq$ FB zio $=\mathrm{MB}$ zio, $\mathrm{M}$ madre $\neq \mathrm{MZ}$ zia $=\mathrm{FZ}$ zia

$$
\begin{aligned}
\mathrm{FS} & =\text { MS fratello } \neq \text { FBS cugino }=\text { FZS cugino } \\
& =\text { MZS cugino }=\text { MBS cugino }
\end{aligned}
$$

Exactly comparable changes have occurred between Old Russian and modern Russian. Data like this suggest linked transitions between tightly integrated systems, though remain agnostic as to timing and mechanism. The Italian/ Russian example illustrates what we term the "internal coselection hypothesis": that changes in systems of kinship terminology involved linked sets of changes between different parts of the system; furthermore, that internal co-selection can be detected in synchronic records of a broad sample of languages by the relative lack of "mixed" system types, and the predominance, near or universal, of "harmonic" types such as those implied by the classic typologies.

On the other hand, if our global sample attests substantial numbers of what classic treatments would have regarded as many "mixed" types, then diversity will be much greater. On this account, changes between systems may be much more piecemeal, since a change in the range of one term may only have weak (or no) consequences for other parts of the system. Whether or not the classic types are robust is not merely a matter for kinship scholars. These essentializing types remain vibrant in pedagogical literature (e.g., Stone 2013; Parkin 1997) and have had new use as predictor variables in recent cross-cultural work in, for example, economics and psychology. Our goal here is an explicit and data-driven account of system coherence that is accessible beyond a narrow audience, allowing the design space of kinship to be freshly considered with 21 st century tools.

The rest of the article is structured as follows. In the "Classic Typologies of Kinship" section we review the main typologies of kinship, their predictions, and some of the problems they have faced empirically. In the "Our Database" section we introduce our database. We test coherence with two approaches, focusing on key kin types defined by sibling, cousin, parent, and nuncle terms. In the "Testing Typological Cohesion: Clearing the Ground with New Data" section we use our large dataset to evaluate the empirical adequacy of classic claims about system coherence, to clear ground and establish a descriptive baseline. In the "Testing Typological Cohesion: Introducing New Methods" section we evaluate the same claims using a new computational method, applying multi-dimensional scaling to see how neatly the classical categories cleave apart. This method holds great promise for identifying data-driven clusters in the kinship system design space. We conclude in the "Conclusions on the Internal Coherence of Canonical Types" section by evaluating the extent of coherence across the different parts of terminological systems, what causal 
mechanisms best account for the data we have examined, and what future steps are needed for understanding the shape of kinship systems.

\section{Classic Typologies of Kinship}

The most notable typology of the mid-20th century was designed to capture variation in cousin organization, and is often used as the primary description of a language's terminology (Murdock 1949; Dole 1972). Each type was named after a society that exemplified each system: Eskimo, Hawaiian, Dravidian, Sudanese, Crow, and Omaha. The declaration of a universal set of cousin systems led scholars to extend these to broader kin-terminologies based on perceived patterns of internal and external co-selection. Canonical kinship terminologies (typologies) describing relatives in one's nuclear family, as well as parents' siblings, and parents' siblings' children, were the culmination of work from Kroeber, Lowie, and Murdock who identified and applied the principles of collaterality and bifurcation to derive the first four of the systems listed above (Kroeber 1909; Lowie 1928; Murdock 1949; Godelier 2012). Crow and Omaha systems are then further derived with the addition of generational skewing, where a kin term can be used across generations (e.g., one calls one's "mother's brother's son" by the term for one's "mother's brother"). As ethnographic knowledge increased in scope, the inevitable result was that these six types failed to capture the full design space. Murdock himself worked with codes that acknowledged differences in ego and parent generations (1970); subsequent debates have raged about types, subtypes, and exceptions (e.g., Iroquoian types, Kariera types, Dravidian subtypes) (Romney and Epling 1958; Lounsbury and Goodenough 1964; Godelier et al. 1998). This debate has led some kinship theorists to call for a typological rethink (Kronenfeld 2004, 2006), or to propose an alternative generative focus on kinship terminologies (Jones 2010; Read 2013), although no one approach has gained the traction still held by the classic typology (e.g., Cronk et al. 2019). Despite these developments, it is useful to begin with the major types in terms of ego's $\left(\mathrm{G}^{0}\right)$ and the parental $\left(\mathrm{G}^{+1}\right)$ generations, making the simple assumption that the terminologies in these two generations are mutually consistent.

\section{Hawaiian}

The canonical Hawaiian kinship system terminologically divides kin by generation and gender. This results in four terms that can be represented by the following rules: ${ }^{9}$

$\mathrm{F}=\mathrm{FB}=\mathrm{MB}$

$\mathrm{M}=\mathrm{FZ}=\mathrm{MZ}$

$\mathrm{B}=\mathrm{FBS}=\mathrm{MBS}=\mathrm{FZS}=\mathrm{MZS}$

$\mathrm{Z}=\mathrm{FBD}=\mathrm{MBD}=\mathrm{FZD}=\mathrm{MZD}$

These rules generally represent the cultural kin-categories of a male in the generation above, a female in the generation above, a male in my generation, and a female in my generation. The syncretisms across parents and parent's siblings (male and female) in $\mathrm{G}^{+1}$ are often echoed by syncretisms in the $\mathrm{G}^{0}$ generation between siblings and parents' siblings' children. That is, if all $\mathrm{G}^{+1}$ women are terminologically equivalent, then it seems natural that we should also see the syncretism reflected in their children. It is important to emphasize that organization in $\mathrm{G}^{+1}$ does not cause the organization in $\mathrm{G}^{0}$ (or vice versa), but merely that there is a process of co-selection in terms of a natural fit between terminological systems in the two generations.

\section{Eskimo}

Eskimo terminologies distinguish lineal family members (up and down the direct line of descent), from collateral kin (off to the side of this direct line), and collapse kin terms for collateral kin (e.g., the two types of uncles [FB, MB] and aunts [FZ, MZ]). Within $\mathrm{G}^{0}$ and $\mathrm{G}^{1}$ this system results in seven (as in English, which does not distinguish cousins by sex) or eight terms (taking French, Spanish, or Italian as an example).

$\mathrm{F} \neq \mathrm{FB}=\mathrm{MB}$

$\mathrm{M} \neq \mathrm{FZ}=\mathrm{MZ}$

9 An interesting outgrowth of the kinship literature parametrized the typologies by proposing axiomatizations of different kinship systems as different sets of merging rules (or "equivalence rules") by Lounsbury (1964, 1965; Scheffler 1978), which are essentially polysemic extensions that can apply recursively at indefinite distance from ego. One way of summarizing the findings of this article is that counter to the Lounsbury/Scheffler approach, rules of equivalence cannot automatically be combined in a generative way: rather than simply allowing them to interact, in many languages they form small, potentially isolated pockets of equivalence that require local statements. 


$$
\begin{aligned}
\mathrm{B} \neq \mathrm{MZS} & =\mathrm{MBS}=\mathrm{FZS}=\mathrm{FBS}=\mathrm{MZD} \\
& =\mathrm{MBD}=\mathrm{FZD}=\mathrm{FBD} \neq \mathrm{Z}
\end{aligned}
$$

or

$\mathrm{B} \neq \mathrm{MZS}=\mathrm{MBS}=\mathrm{FZS}=\mathrm{FBS}$

$\mathrm{Z} \neq \mathrm{MZD}=\mathrm{MBD}=\mathrm{FZD}=\mathrm{FBD}$

These rules distinguish nuclear family members from other relatives and ignore lineal distinctions in parent's siblings and their children. The cultural importance of nuclear families has often been considered an external selective force on this type, but there is sizable variance in the social organization of societies using this system (Hughes 1958). In a similar vein to Hawaiian systems, we can see co-selection as accounting for the "harmony" between the $\mathrm{G}^{+1}$ and $\mathrm{G}^{+0}$ generations, since the lineal versus collateral distinction in the parents' generation is propagated into a similar distinction (between siblings and cousins) in ego's generation.

\section{Dravidian Systems}

Dravidian systems are distinguished from the previous two types by introducing crossness. This is where parent's opposite-sex siblings ("cross") are terminologically different to their same-sex siblings ("parallel"). Internal co-selection then predicts the similar cross-sex pattern seen in the descending generation, although we will see counterexamples in "Testing Typological Cohesion: Clearing the Ground with New Data" section, in both directions. A canonical Dravidian system is described with the following rules:

$\mathrm{F}=\mathrm{FB} \neq \mathrm{MB}$

$\mathrm{M}=\mathrm{MZ} \neq \mathrm{FZ}$

$\mathrm{B}=\mathrm{FBS}=\mathrm{MZS} \neq \mathrm{FZS}=\mathrm{MBS}$

$\mathrm{Z}=\mathrm{FBD}=\mathrm{MZD} \neq \mathrm{FZD}=\mathrm{MBD}$

Dravidian systems are closely linked to cross-cousin marriage practices (Lounsbury 1964), and previous analysis by Désveaux and Selz (1998) used logical inference predicated on the practice of cross-cousin marriage to infer the structure of a Dravidian terminology. In both Australia and southern India, for example, a widespread conjunction of marriage prescriptions and kinship terminology combines crosscousin marriage (e.g., between a man and his FZD) with a terminological syncretism between the consanguineal term FZ and the affinal term WM-since, if the marriage rules are followed, one's father's sister IS one's wife's mother. This is a nice example of evidenced external co-selection between a marriage rule and a particular syncretism in the system of kinship terminology; we do not pursue this further, since to systematically bring in affinal terms is beyond the scope of this article.

\section{Sudanese Systems}

A canonical Sudanese system distinguishes all structural positions in the parents' generation (i.e., siblings on each side have their own term), and the cousin terms track these distinctions. Such systems thus eliminate all syncretisms relevant to the major typologies.

$$
\begin{aligned}
& \mathrm{F} \neq \mathrm{FB} \neq \mathrm{MB} \\
& \mathrm{M} \neq \mathrm{MZ} \neq \mathrm{FZ} \\
& \mathrm{B} \neq \mathrm{FBS} \neq \mathrm{MZS} \neq \mathrm{FZS} \neq \mathrm{MBS} \\
& \mathrm{Z} \neq \mathrm{FBD} \neq \mathrm{MZD} \neq \mathrm{FZD} \neq \mathrm{MBD}
\end{aligned}
$$

Murdock (1967, 1970) distinguished between Sudanese and Descriptive types, which are structurally the same but differ in whether the terms are internally analyzable. Danish, for example, would be considered a Descriptive type in the parents' generation, since FB is farbror (far "father," bror "brother"), MB is morbror (mor "mother"), and FZ and MZ are the only slightly less transparent faster and moster (combining fa $<$ far and mo $<$ mor with -ster $<$ søster "sister"). We set aside this distinction here, because (a) we consider the question of how far terms can be morphologically broken down to be independent of the semantic structure of the system, (b) formal resemblances can be found in kinship systems of all types (from totally to partially compositional), not just Sudanese, and (c) we can use separate methods (outlined in section "Testing Typological Cohesion: Introducing New Methods") to factor in formal lexical similarity should we wish to go beyond a "same versus different" judgment.

\section{Crow/Omaha}

The previous four systems are defined by syncretisms (or lack of syncretisms) within generations. Crow and Omaha systems are defined by their syncretisms across generations, often called generational skewing, where certain cousins $\left(\mathrm{G}^{0}\right)$ are terminologically equated with certain nuncles $\left(\mathrm{G}^{+1}\right)$. These systems are effectively mirror opposites: Omaha systems skew along patrilineages, and Crow systems skew along matrilineages. This is highlighted in the second rule for Omaha, and the first rule for Crow, below; the "skewing" syncretisms are shown in bold. 
Omaha

$\mathrm{F}=\mathrm{FB} \neq \mathrm{MB}=\mathbf{M B S}$

$\mathrm{M}=\mathbf{M Z}=\mathbf{M B D} \neq \mathrm{FZ}$

$\mathrm{B}=\mathrm{MZS}=\mathrm{FBS} \neq \mathrm{FZS}$

$\mathrm{Z}=\mathrm{MZD}=\mathrm{FBD} \neq \mathrm{FZD}$

Crow

$\mathrm{F}=\mathbf{F B}=\mathbf{F Z S} \neq \mathrm{MB}$

$\mathbf{M}=\mathbf{M Z} \neq \mathbf{F Z}=\mathbf{F Z D}$

$\mathrm{B}=\mathrm{FBS}=\mathrm{MZS} \neq \mathrm{MBS}$

$\mathrm{Z}=\mathrm{FBD}=\mathrm{MZD} \neq \mathrm{MBD}$

The skewing illustrated here is restricted to $\mathrm{G}^{0}$ and $\mathrm{G}^{+1}$ and these rules represent a typical Omaha or Crow system, though there are languages that propagate the skewing right down the generations of a matriline or patriline. The nature of skewing in each of these systems has been noted as a result of external co-selection by strong patrilineal and matrilineal descent norms. For example, in the Omaha system, both one's MB and one's MBS are "male members of one's mother's patriclan."

Two types of definitional problems beset the assignment of a system to Crow or Omaha types: cross-generational equivalences can involve other-generation pairs beyond the classic nuncle/cousin syncretisms of Crow/Omaha types. Cross-generational equivalences can involve other-generation pairs beyond $\mathrm{G}^{0}$ and $\mathrm{G}^{+1}$ generations, e.g., every second generation in a matriline (Levinson 2006), or between nephews/nieces and grandchildren (Italian nipote), in neither case involving $\mathrm{G}^{0}$. Similarly, syncretisms may fall within the $\mathrm{G}^{0}$ and $\mathrm{G}^{+1}$ generations, but involve siblings rather than cousins, as with the Maya-Mopan (Guatemala) rule $\mathrm{eB}=\mathrm{FyB} \neq \mathrm{FeB}=\mathrm{PF}$; this syncretism is attributed to cultural roles in provisioning for children (Danziger 1993).

We do not treat Crow and Omaha systems separately for the purposes of this article. This is because they are defined by syncretisms across generations, but do not exhibit distinctive characteristics in their behavior within generations, so that for the purposes of looking at how far there are correlations between the within-generation syncretisms in our two chosen generations $\left(\mathrm{G}^{0}\right.$ and $\left.\mathrm{G}^{+1}\right)$ any cross-generational skewing is irrelevant. Thus, we code both Crow and Omaha systems as Dravidian, in both generations, since in each of them $\mathrm{F}=\mathrm{FB} \neq \mathrm{MB}$, and $\mathrm{B}=\mathrm{MZS}=\mathrm{FBS} \neq \mathrm{FZS}$.

\section{The Classic Typology: Recap}

Our exposition in this section has focused on the classic canonical systems. Amongst kinship typologists there has been a steady multiplication of system types and subtypes, many of which surround the intensively-studied cross/parallel distinction (Godelier et al. 1998). The Dravidian type (above) and Iroquois type, both of which are identical in $\mathrm{G}^{+1}$ and $\mathrm{G}^{0}$, but differ when more distant relations and affinal terms are taken into account, make different predictions about the external co-selection of cross-cousin marriage (Trautmann 1981). Likewise, debate continues on whether the increasing number of subtypes requires a typological rethink, or can be accommodated by treating the awkward cases as transitional terminologies (Kronenfeld 2006; Godelier 2012).

From here we explore a radically different approach, which abandons the assumption of definitional coherence between different patterns of syncretism, and systems themselves. Our start point is to acknowledge the large design space-that any combination of syncretisms is possible between any kin types. Using computational methods, we can take a data-driven approach that incorporates all kin terms, rather than selecting particular focal kin types to represent a whole language system. Recurrent patterns like the canonical systems above certainly do occur, but so do many other combinations, and these can be explored and characterized without the need to start with, or shoehorn them into, existing typologies.

\section{Our Database}

\section{Languages}

The Kinbank database contains 1,107 languages, with data on about 98 kin types for most languages and 473 different kin types for which data is given in at least some languages. Our kin types cover relatives from $\mathrm{G}^{-2}$ and $\mathrm{G}^{+2}$, including collateral kin and their affines. The database holds a global sample of languages from 21 language families, with strong representation from large language families (e.g., Austronesian (375), Atlantic-Congo (117), Pama-Nyungan (104), and Indo-European (104)) but equally broad coverage of all regions and smaller families; it is therefore useful for both global and within-language family analysis. Data were collected from the ethnographic and linguistic literature and/ or from native speakers (see Passmore et al. (in prep.) for details). 


\section{Kin Types}

The kin types broadly cover: parents, siblings, children, children's children, sibling's children, parent's siblings, parent's sibling's children, and parent's parents. All kin types include specification of the sex of speaker, and within $\mathrm{G}^{0}$ and $\mathrm{G}^{+1}$ we additionally account for relative age, and relative age of the linking relative (e.g., the FeBD of a woman). Affinal terms are also systematically collected for the partners of ego, of parent's siblings, of ego's siblings, and ego's children, with additional relationships added when available. ${ }^{10}$

The database is a collaborative result of three overlapping but separately-funded projects, ${ }^{11}$ and thus presented an opportunity to assess sources of data interpretation error by determining intercoder reliability. All teams collected kin terms on the same 44 languages (from the same or different sources). Using a vector-comparison approach (explained in the "Testing Typological Cohesion: Introducing New Methods" section) we calculated the structural similarities on each teams' complete set of kin terms sets to be 0.8. See Passmore et al. (in prep.) for further details. For the analyses in the next two sections we used subsets of the full database as coverage allowed.

\section{Testing Typological Cohesion: Clearing the Ground with New Data}

Underlying the kinship typology approaches in the "Classic Typologies of Kinship" section, above, is the assumption that kinship systems (like other systems beloved by structuralist linguistics) are "systems where everything holds together." 12 This is an appealing and sensible idea: to formulate a concept like cousin in English, it helps that our terms for the linking

\footnotetext{
${ }_{10}$ A full list of parameters is available at https://github.com/kinbank/ kinbank/blob/master/kinbank/cldf/parameters.csv

11 VARIKIN, Museu Paraense Emilio Goeldi, and PARABANK (which in turn is part of the Glottobank consortium). VARIKIN was primarily built by researchers at the University of Bristol, particularly Passmore and Jordan, with MPEG data collection by Joshua Birchall, Luis Henrique Oliveira, and Fiona Jordan; Parabank has primarily been built by researchers based at the ARC Centre of Excellence for the Dynamics of Language, particularly Barth, Evans, Greenhill, and Quinn.

12 In linguistics the classic line "un système où tout se tient" has been employed for over a century, variously attributed to Saussure and Meillet. See Koerner (1997) on the complex paper trail of this attribution.

13 A variation on the everything-holds-together scenario was proposed by D'Andrade (1971, p. 74), who modulates it by allowing new distinctions to first take hold in the +1 generation, and then spread to the +0 generation, but never the other way round. This will add in, with relatively low occurrence, "transitional" types in which the distinction has entered the +1 generation without yet entering the 0 generation, but never the reverse case in which the 0 generation makes the distinction but this is not found in the +1 generation.
}

relative are nicely set up to define it as "child of an uncle or aunt" and are neither too broad and imprecise, nor too narrow and precise, nor — worst of all—merge and diverge according to a different pattern. ${ }^{13}$ Terms for the linking relative would be too imprecise if, Hawaiian-style, we had just a single word funcle taking in fathers and all uncles: defining cousin as "child of a funcle" wouldn't work because some children of funcles would be my siblings and some would be my cousins. And a Sudanese type system would be too precise, if we can render funcle for father's brother and muncle for mother's brother, as well as faunts for father's sisters and maunts for mother's sisters-we would then have to define cousins as the children of uncles, muncles, funcles, aunts, faunts, or maunts. Do not worry if you are confused-that is the whole point. It is hard to reason about terminology in applying the native terms if systems mix and match the layout of their mapping of kin terms onto types between generations.

The commonsense insight, that it is sensible for systems of kinship terminology to be logically harmonic across different subsystems, was responsible for the types discussed in section two in the first place, and has been recently explored in new ways with cognitive modelling by Kemp and Regier (2012). It underlies the fact that some of the most influential kinship typologies (Lowie 1928; Kirchhoff 1932) were based on terms in the $\mathrm{G}^{+1}$ generation, while others (Murdock 1949) were based on $G^{0}$, yet they reached essentially the same types.

Despite mounting ethnographic counterexamples (see Pans (1967) and Murdock (1970) for a more nuanced view), these convenient and intuitively neat typologies have endured as shorthand for decades, particularly in the pedagogical realm. Kinship specialists have made admirable attempts at interrogating their consistency, but for the most part start with these types, usually adding new mixed patterns to account for variation. It is not, however, possible for a human brain to systematically compute the vast combinatorial possibilities presented by even a small set of kinship types and terms to cover them. With our large global dataset, and greater computational power, we have the opportunity to test these internal correlations robustly. We outline two methods to examine internal co-selection.

Our first method uses partial informativeness as a criterion: what does knowing about one part of the system provide us in knowing about another part? The kinship categories are compared as a unit independent of the actual term used $^{14}$ and we confine ourselves to terms for the parents'

\footnotetext{
${ }^{14}$ Murdock (1968) tested an idea by Pans (1967) that the kinship system emerges from within the terminological system itself. He compared cousin and sibling subsets and found only a weak correlation mostly due to languages that spell out the biological relation in the terminology, e.g., Danish (see above). Therefore, we do not consider term-internal structure in our study.
} 


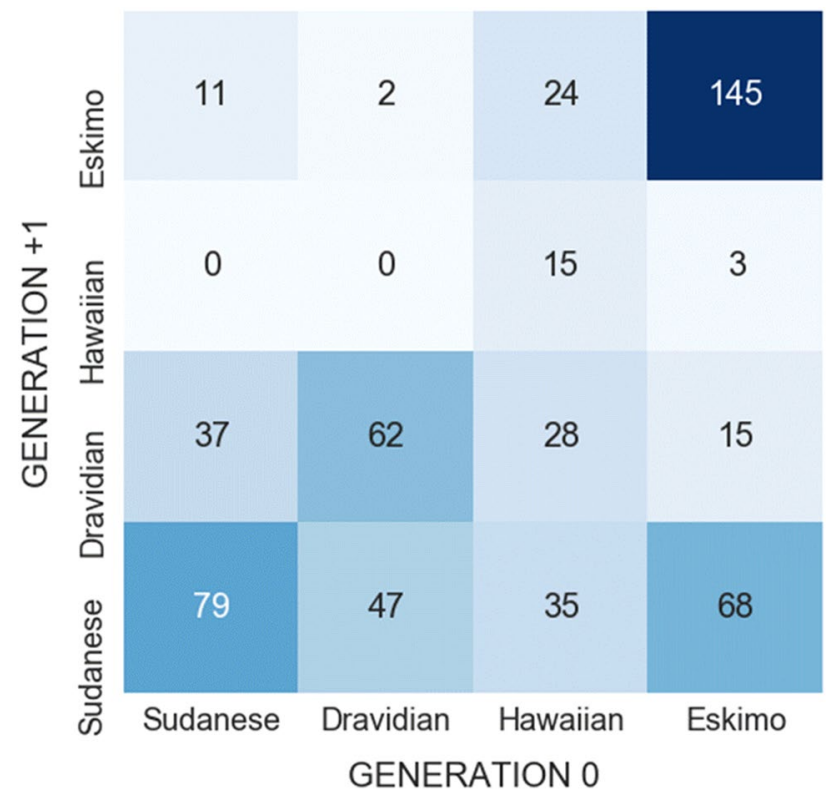

Fig. 1 Patterning of kinship terms across $G^{+1}$ and $G^{0}$ in 571 languages from a global sample. Each cell contains the number of languages with that particular combination of classic kinship system features for $\mathrm{G}^{+1}$ and $\mathrm{G}^{0}$ and is shaded for density (darker=combination is more frequent in the sample)

and ego's generations, making some simplifying assumptions to deal with the potentially complicating effects of finer terminological splits. Thus, if a system distinguishes father's older brother from father's younger brother, we just examine the father's older brother term in comparisons with the father or mother's brother term. Likewise, for cousins, we only included the comparison brother: male cousin (and, if relative age enters the picture, using "older" as the default). Note that a rather similar technique to assess how far the types in the $\mathrm{G}^{+1}$ and $\mathrm{G}^{0}$ generations correlate, by constructing a two-dimensional array, and then seeing how many languages populate each cell in the total space, was carried out by D'Andrade (1971). He found a far lower degree of dimensional independence than we do, probably reflecting his smaller dataset.

For each language, we then categorize the terms in each of these two generations using the basic four-way classification set out in the "Classic Typologies of Kinship" section. For example, English would be categorized as "Eskimo" in both parents" and ego's generation, Latin as "Sudanese" at both levels, and Kayardild as "Dravidian" at both generational levels. Kuikuru (Brazil), however, contains "Hawaiian" in ego's generation, and "Iroquois" in the parental generation, and this combination occurs 13 more times in Murdock's (1949) sample (Dole 1969). This gives us a two-way classification for each of our 571 languages, one at each of the two generational levels. In principle this gives us sixteen possibilities as the two four-way distinctions are crossed. If there is complete coherence across systems, only four of the sixteen cells should be filled, namely those along the diagonal, and they should be harmonic, in the sense of being of the same type in both generations. If anything goes, and there is no relation between the patterning of $\mathrm{G}^{0}$ or $\mathrm{G}^{+1}$ terms, all sixteen cells should be equally populated. Figure 1 shows our results.

Two striking features emerge. First, all but two cells are filled by at least some languages. Straight away, we can see that the data does not support strict system coherence: far from it. Only Hawaiian $\mathrm{G}^{+1} /$ Dravidian $\mathrm{G}^{0}$, and Hawaiian $\mathrm{G}^{+1} /$ Sudanese $\mathrm{G}^{0}$, are not represented in our sample. If a system merges parents and nuncles, Sudanese or Dravidianstyle partitions of the sibling/cousin space are precluded. But of the 16 possible combinations, only those two are heavily constrained. We then ask: what combinations are most common?

Systems do display some harmony. While the diagonal contains three of the most populated cells, as predicted by strong internal co-selection (Eskimo/Eskimo (ranked 1st), Sudanese/Sudanese (ranked 2nd), Dravidian/Dravidian (ranked 4th)), the Hawaiian/Hawaiian combination has only 15/573 languages (ranked 10th). Overall, the diagonal accounts for only half $(52.7 \%)$ of all the data, while offdiagonal cells are at 10-15 times the frequency that Murdock (1949) found. Non-harmonic cells well-attested in our data are Sudanese $\mathrm{G}^{+1} /$ Eskimo $\mathrm{G}^{0}$, Sudanese $\mathrm{G}^{+1} /$ Dravidian $\mathrm{G}^{0}$, and Dravidian $\mathrm{G}^{+1} /$ Sudanese $\mathrm{G}^{0}$, and these are present at appreciable frequencies. This suggests that between-generation informativeness is variable, and type-dependent. ${ }^{15}$

\footnotetext{
$\overline{15}$ Charles Kemp (personal communication, 2021) draws on Greenberg (1966) to construct a concrete prediction. Systems can be arranged in a connected network with the most complicated (Sudanese) at one end, and the least (Hawaiian) at the other, with the possibility of transitioning between Sudanese and Hawaiian mediated by either the Eskimo or the Dravidian path, but not both. This would then predict a possibility matrix in which intermediate systems exhibiting features from two neighboring points could exist, but not others. In other words, Eskimo and Dravidian can both be reached by neutralizing some of the Sudanese distinctions, but are mutually incompatible. This generates a $4 \times 4$ matrix permitting (+ 1 types given first) Esk/Haw, Esk/Esk, Haw/Haw, Drav/Drav, Drav/Haw, Sud/Sud, Sud/Drav/Sud/Hawaiian. This proposal does in fact correlate broadly with the distribution of our sample, except that Dravidian/Sudanese (37 instances), one of the purportedly impossible types, is in fact more common than some of the purportedly possible types, such as Eskimo/Hawaiian (24), Hawaiian/Hawaiian (15), Dravidian/Hawaiian (28), and Sudanese/Hawaiian (35). We also find other types predicted not to occur on this account, namely Eskimo/Sudanese (11), Eskimo/ Dravidian (2), Hawaiian/Eskimo (3) and Dravidian/Eskimo (15).
} 
While for each classic "type" knowing the pattern in $\mathrm{G}^{+1}$ is informative for $\mathrm{G}^{0}$ and vice versa, the effect is not equally strong for all types. Knowing $\mathrm{G}^{0}$ works moderately well for Eskimo and Sudanese (both $62 \%$ harmonic), and Dravidian $(56 \%)$, but for Hawaiian $\mathrm{G}^{0}$ gives very little predictive power (15\%). From the other direction, knowing $\mathrm{G}^{+1}$ neatly predicts the harmonic state for Eskimo (80\%) and Hawaiian (83\%), but much less so for Dravidian (44\%) and Sudanese $\mathrm{G}^{0}(35 \%)$. Furthermore, predicting the most likely non-harmonic combination is not only type-dependent, but generation-dependent: the non-harmonic types that Dravidian $\mathrm{G}^{0}$ is informative on are not the same as what Dravidian $\mathrm{G}^{+1}$ is informative on. We use Cramer's V statistic to quantify the degree of intergenerational correlation between kinship systems $(0=$ no correlation, $1=$ perfect correlation $)$, and obtain 0.395 , at the high end of moderate. Coupling between system types across generations is present, but this internal co-selection is not strong or deterministic. ${ }^{16}$

To test whether our global results might be distorted by language-family or macroregional bias, we compiled comparable diagrams for the main language families (Fig. 2) and regions (Fig. 3) in our database. As anthropologists have observed, many families either have one (e.g., Sudanese in Algic and Atlantic Congo, Eskimo in Austronesian) or two dominant types (e.g., Eskimo and Sudanese in Indo-European), reflecting some degree of conservatism and phylogenetic signal at the family level (Passmore and Jordan 2020). This is not universal: some families (Pama-Nyungan) and macro-regions (Eurasia, South America) have their most populous patterns in cells that are disharmonic between $\mathrm{G}^{0}$ and $\mathrm{G}^{+1}$. Our finding above is that there is (at best) a moderate harmonic correlation between term systems across the two generations; however, this only emerges when we pool our global data, and is not evident in the data from any one family. The large Austronesian family is especially illustrative here: it explores the design space to almost the same degree as the worldwide sample (in the sense of only three empty cells) but has a less pronounced diagonal, indicating weaker correlations between terms in the two generations.

With this first test of internal cohesion, our data suggest that the classic typologies have limited predictive value when it comes to the co-selection between the generational subsystems of parents' and ego's generation. Harmonic correlations are indeed present, but these are weak, and some disharmonic conjunctions are equally frequent. Internal

\footnotetext{
16 A reviewer suggests that our findings might simply replicate those of D'Andrade (1971). However, there are substantial differences between our findings and his, probably reflecting our much larger sample. Most importantly, where he found that "rarely, ... i.e. five times in 678 cases, or less than $1 \%$ of the time" (p. 64) a distinction occurs in $\mathrm{G}^{0}$ without the same distinction in $\mathrm{G}^{+1}$, whereas we find this for $12.2 \%$ of the cases, i.e., $77 / 631$.
}

consistency, as a cognitive and/or cultural driver, may be just one of many low-level selective forces favoring one pattern of syncretism (at system level) over another.

\section{Testing Typological Cohesion: Introducing New Methods}

In this section we build on the finding that internal consistency, using the classic typology of systems, is limited. We explore the cross-linguistic variation in $\mathrm{G}^{0}$ terms using a method that allows fine-grained characterization from the bottom-up. Recall from the "Classic Typologies of Kinship" section that the classic typology was designed to categorize the organization of cousin/sibling terms, and while kinship specialists have long acknowledged that the systems are idealized (and that languages are not exact replicates of these systems), very little work has explored the extent and implications of this variation.

Here we aim to shift thinking from strict canonical systems to probabilistic clouds, using vector-based representations of the $\mathrm{G}^{0}$ space. On this view of kinship, we can think of languages varying within a continuous space where closeness indicates similarity and distance indicates difference. We demonstrate this with a simplified example. Consider the kin terms in $\mathrm{G}^{0}$ for two languages with different systems (Fig. 4). For each language, we compare each kin type to every other type, and note the presence $(=1)$ or absence $(=0)$ of a syncretism, i.e., the same term is used for that pair of relatives. With this approach, we create an exhaustive binary vector representing the patterns of syncretism for each language-and for the canonical systems themselves. We can then compare languages via their vectors to assess the similarities and differences in patterns of syncretisms. Two languages with the exact same kinship system will match at each position in the vector, and the sum of matches divided by the total number of pairs gives a measure of structural similarity, where a score of 1 will indicate an exact structural match. ${ }^{17}$ In our analysis below we take a step further to use string information from each kin term to give partial matches, rather than binary all-or-nothing matches. Computationally, we can then use this information with dimension-reduction methods, and represent the position of each language in a multidimensional space.

Since we can define vectors for each of the canonical systems, the distance of any language from these vectors indicates how well it fits to the classic typology. By representing languages as taking a position in a graded kinship space, we open up important and previously intractable questions. Are

\footnotetext{
$\overline{17}$ We used this approach to test for inter-rater reliability in the "Our Database" section.
} 


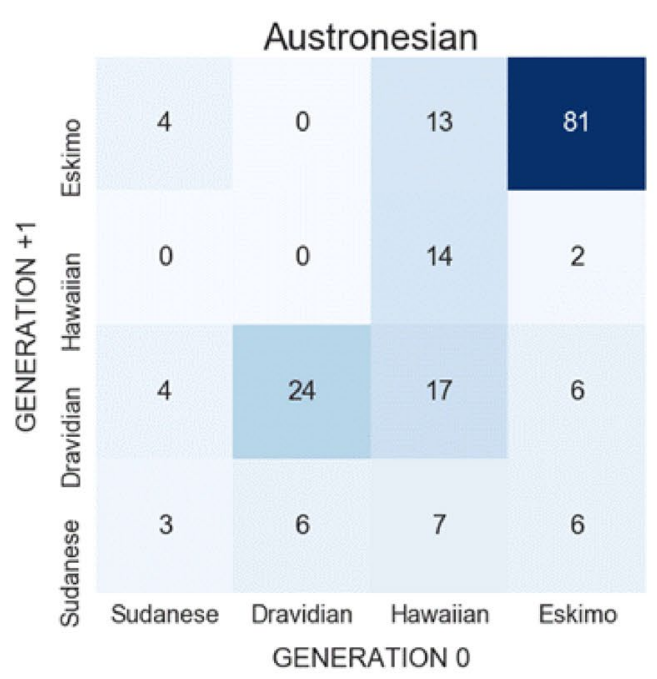

Algic
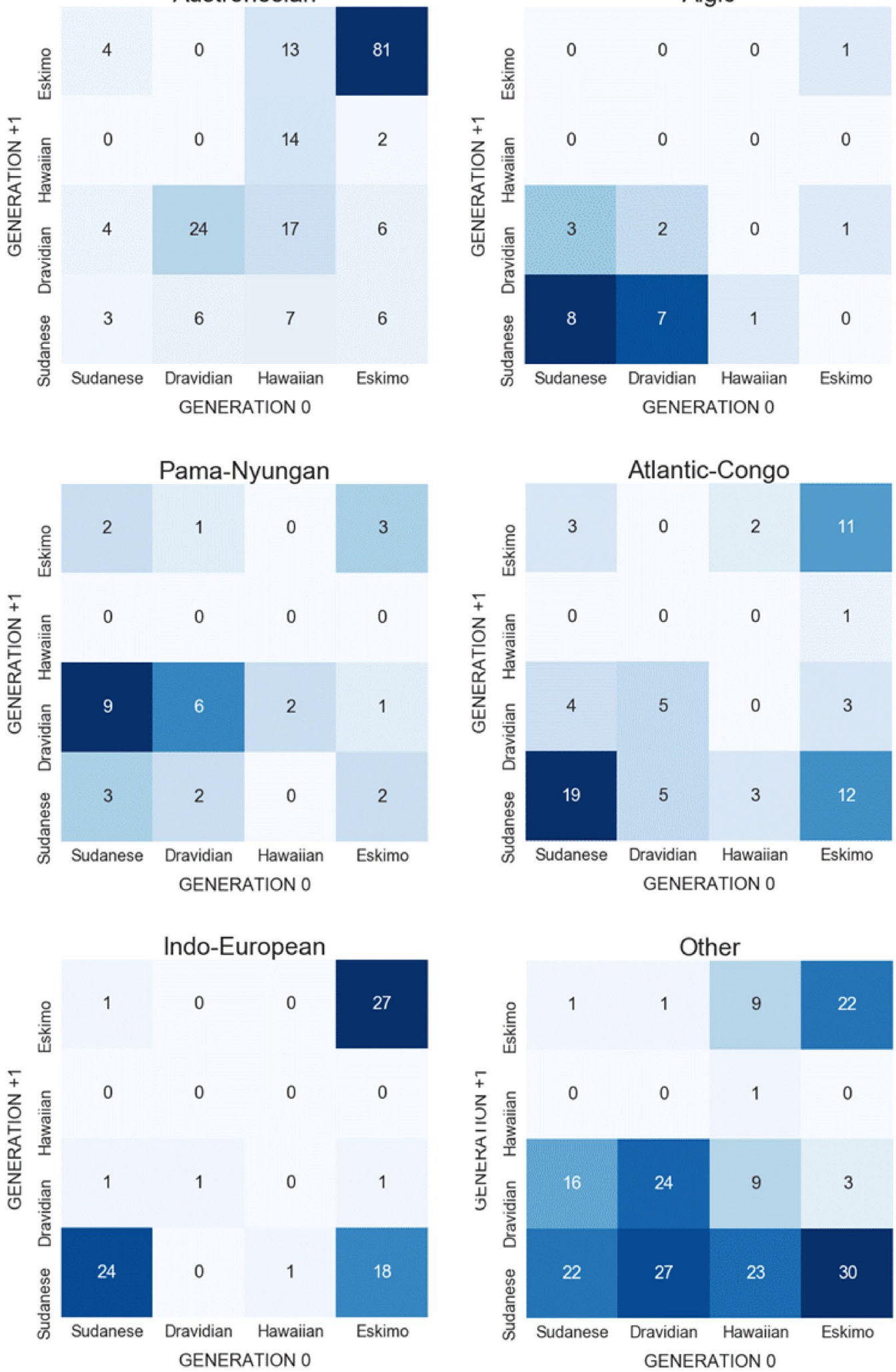

Fig. 2 Patterning of kinship terms across $\mathrm{G}^{+1}$ and $\mathrm{G}^{0}$, by language family 

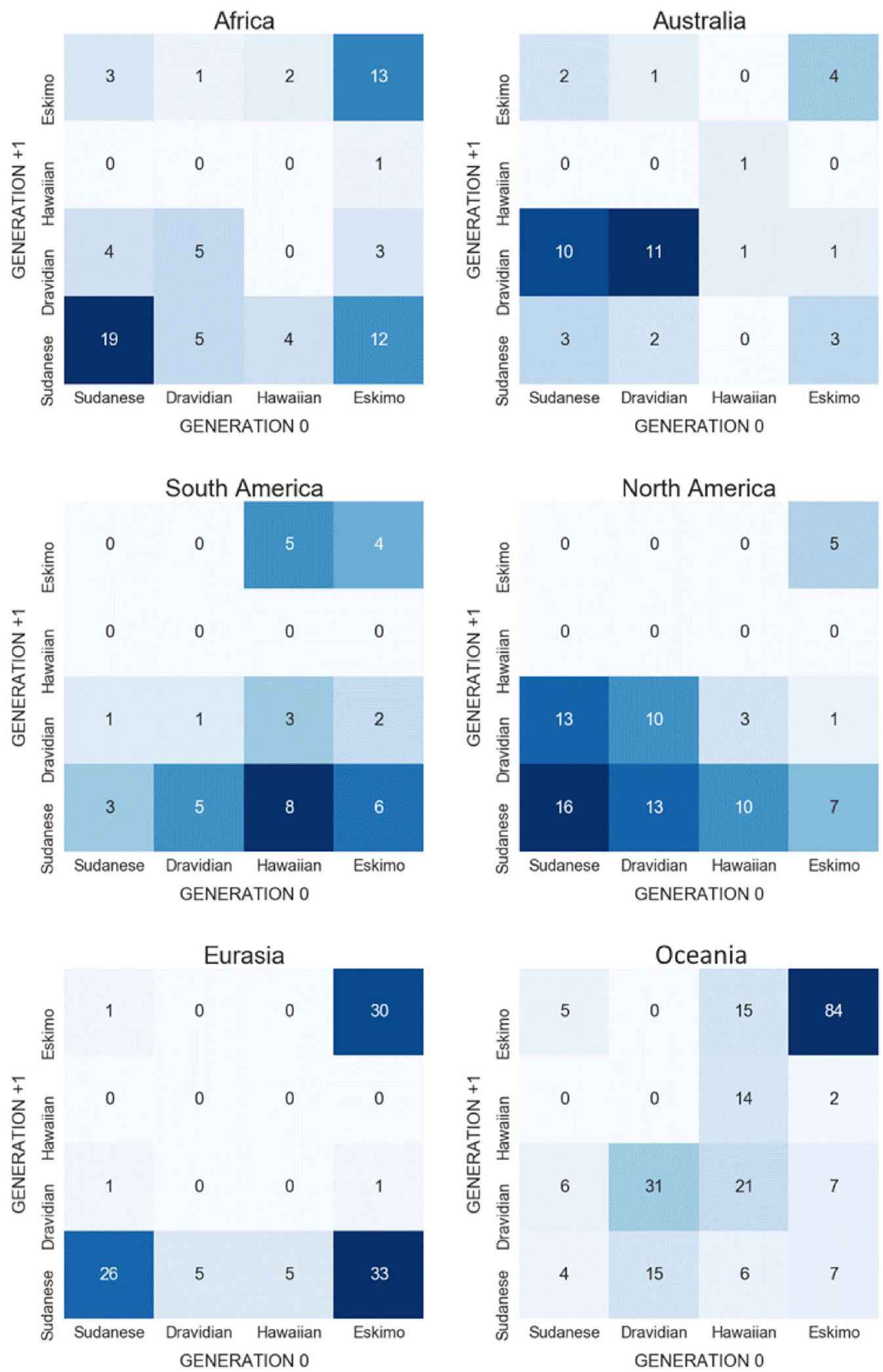

Fig. 3 Patterning of kinship terms across $\mathrm{G}^{+1}$ and $\mathrm{G}^{0}$, by macro-region. Oceania includes New Guinea and the islands of the Pacific 
Fig. 4 Representation of kinship terminology systems as a binary string; differences in binary strings then represented in multidimensional space. a $\mathrm{G}^{0}$ for canonical Eskimo and Iroquois with same hues showing the same terms are used for those relatives. b Each term is compared to each: same terms are scored as 1 , different as 0 . c Binary strings obtained for each language (string length is 780 for the comparisons in our study). d Dimension-reduction techniques used to represent languages in space; closer systems are more similar in their patterns of syncretism

A

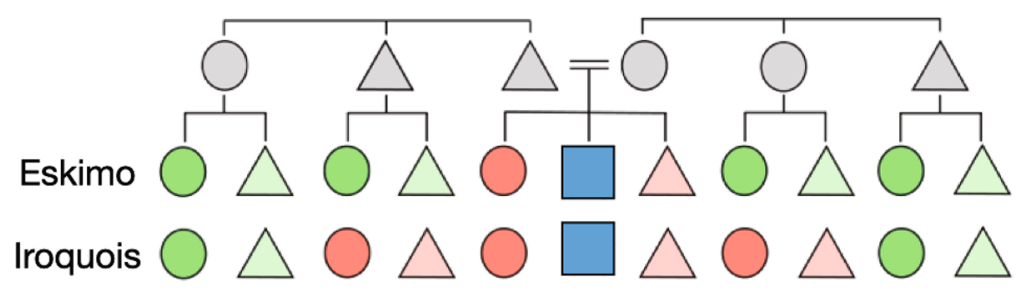

B

\begin{tabular}{c|c|c|c|c|c} 
& FBD=MZD & FBD=MBD & Z=MZD & FBD=FZD & $\ldots$ \\
\hline Eskimo & 1 & 1 & 0 & 1 & 1101001 \\
\hline Iroquois & 0 & 1 & 1 & 0 & 1010001
\end{tabular}

C

Eskimo $1101001 \ldots$
Iroquois $1010001 \ldots$
Crow $1010001 \ldots$
Omaha $1010000 \ldots$
Hawaiian $1111110 \ldots$
Sudanese $0000000 \ldots$

D.

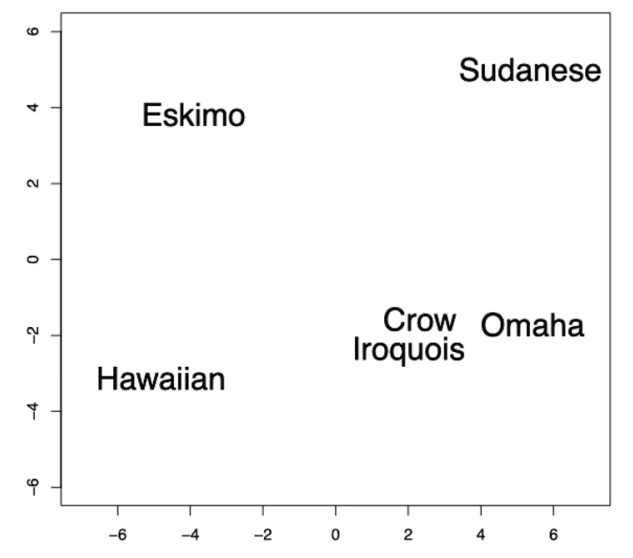

some systems more variable (more of a fuzzy cloud) than others (a tight cluster)? Do systems occupy distinct positions in space or do some overlap? And perhaps most importantly, do the systems that have dominated kinship discourse accurately represent key clusters in kinship space?

To answer these questions, we draw inspiration on logic and methodology from the earlier kinship analysts Nerlove and Romney (1967) and Whiting et al. (1988). As outlined in the first section, the former calculated the design space for sibling terms to have 4140 possible types, of which only 15 occurred with any frequency. ${ }^{18} \mathrm{We}$ expand the analysis of $\mathrm{G}^{0}$ to include parent's siblings' children (cousins), but these additional 16 relationships ${ }^{19}$ create a design space 13

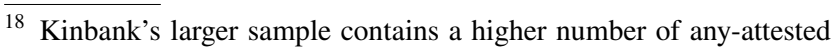
sibling types (116), of which four were more common than Nerlove and Romney's 8th and 9th commonest. Broader sampling (more, and more diverse, languages) and a long-tale distribution would account for this difference.

19 The figure of 16 is obtained by multiplying the four incidences of nuncles (MB, FB, MZ, FZ) times their children of both sexes (male and female) times seniority. Some languages calculate seniority through the linking relative (e.g., FeBS versus FyBS), others through the relative age of ego and the referent (a FBS who is older/younger than ego), but since no language appears to use both principles, and most sources are imprecise about which (if any) of these two criteria operates, we have simply conflated these two principles into "junior/ senior," leaving the criteria unspecified.
}

orders of magnitude larger. The exponentially expanded space introduces significant computational and theoretical difficulties, so instead of replicating Nerlove and Romney exactly we turn to Whiting et al. (1988), who used a multivariate and multidimensional scaling approach to represent observed kinship syncretisms. Their aim was to test Murdock's (1949) proposals of external co-selection, i.e., that social structure and linguistic syncretisms cluster in similar ways, and to evaluate how distinct the clusters were in space. Here, we use powerful dimensionality reduction techniques alongside clustering approaches to create a graded kinship space, allowing the bottom-up assessment of existing systems and their variation.

\section{Creating the Kinship Space}

Our dataset is the subset of Kinbank languages with specification for all siblings and parents' siblings' children kin types, and a corresponding entry in the Ethnographic Atlas (Murdock 1967) for canonical system $(\mathrm{N}=306)$. Accounting for relative age and sex of speaker, this is 40 possible relationships. To apply clustering and dimensionality reduction techniques, we first compared these terms to obtain a numeric structural vector as described in Fig. 4. For each language, a $40 \times 40$ pairwise comparison represented the syncretism structure of the sibling/cousin terminology. Each 
Table 1 Cluster-types in $\mathrm{G}^{0}$ identified from the data by HDBSCAN

\begin{tabular}{|c|c|c|c|c|}
\hline Cluster & $\mathrm{N}$ & Syncretisms & Description & Canonical system \\
\hline A & 69 & [B FBS MZS], [Z FBD MZD], [FZC MBC] & $\begin{array}{l}\text { Syncretisms by gender for siblings and parallel cous- } \\
\text { ins, cross-cousin term }\end{array}$ & Cross-parallel \\
\hline B & 51 & eB, yB, eZ, yZ, [FBC FZC MBC MZC] & $\begin{array}{l}\text { Relative age and gendered sibling terms; single cousin } \\
\text { term }\end{array}$ & Eskimo \\
\hline $\mathrm{C}$ & 35 & e//, eX, y//, yX & Relative age and relative gender distinction across $\mathrm{G}^{0}$ & Hawaiian \\
\hline $\mathrm{D}$ & 21 & B, Z, [FBS FZS MBS MZS], [FBD FZD MBD MZD] & Gendered sibling terms; gendered cousin terms & Eskimo \\
\hline E & 20 & $\begin{array}{l}\text { eB, yB, eZ, yZ, } \\
\text { [FBS FZS MBS MZS] [FBD FZD MBD MZD] }\end{array}$ & $\begin{array}{l}\text { Relative age and gendered sibling terms; gendered } \\
\text { cousin terms }\end{array}$ & Eskimo \\
\hline $\mathrm{F}$ & 19 & $\begin{array}{l}\text { e[B Z FBC FZC MBC MZC] } \\
\text { y[B Z FBC FZC MBC MZC] }\end{array}$ & Elder and younger terms across $\mathrm{G}^{0}$ & Hawaiian \\
\hline G & 19 & $/ /[\mathrm{G} F B C \mathrm{MZC}], \mathrm{X}[\mathrm{G} \mathrm{FBC} \mathrm{MZC}],[\mathrm{FZC} \mathrm{MBC}]$ & $\begin{array}{l}\text { Relative gender distinction for siblings and parallel } \\
\text { cousins; cross-cousin term }\end{array}$ & Cross-parallel \\
\hline $\mathrm{H}$ & 11 & eG, yG, [FBC MZC], [FZC MBC] & $\begin{array}{l}\text { Relative age sibling terms; parallel cousin term; cross- } \\
\text { cousin term }\end{array}$ & Cross-parallel \\
\hline I & 10 & $\mathrm{~B}, \mathrm{Z}, \mathrm{FBC}, \mathrm{FZC}, \mathrm{MBC}, \mathrm{MZC}$ & $\begin{array}{l}\text { Gendered sibling terms; unique term for children of } \\
\text { each parent's sibling }\end{array}$ & Sudanese \\
\hline Outlier & 51 & - & Outlier & - \\
\hline
\end{tabular}

Types are ordered by frequency of occurrence $(\mathrm{N}=306)$. The Syncretisms column shows kin types using the same term in brackets; verbally described in Description column. Canonical System lists the nearest canonical match for the cluster-type

pair of terms was compared using Optimal String Alignment (OSA; a restricted Damerau-Levenshtein distance (Damerau 1964; Levenshtein 1966)). This method compares letters and gives a value between 0 and 1 for each comparison between two terms. A 1 indicates the terms are exactly the same, while 0 indicates that no letters overlapped between the terms: thus, the English pair FBC (cousin) versus FZC (cousin) would score 1 , the terms for MZ (aunt) and $\mathrm{M}$ (mother) would score 0, while the Italian pair FBS (cugino) and FBD (cugina) would score 0.83 . OSA distance allowed us to minimize the impact of grammatical features denoting, e.g., gender. For example, Spanish cousin terms are primo (masc.) and prima (fem.); a simple binary comparison would assign this pair a score of 0 , but would conceal the fact that the underlying semantic structure is the same (cousin in both cases) except for the gender suffix o/a. To create the structural vector for a language, we turn the matrix of pairwise comparisons into a single row. This process is repeated for each language, resulting in a matrix where rows represent languages, and columns represent term comparisons (features).

The distance between each row of the matrix is a function of how similar the structure of each language kinship terminology is (lower distances $=$ more similar systems). Since the number of dimensions in our resultant matrix is high (780 features), we use a technique called HDBSCAN (hierarchical density-based spatial clustering of applications with noise) that identifies key clusters in the kinship space (given in Table 1). We set two parameters in the HDBSCAN algorithm: The first was minimum cluster size which we conservatively set to 10 , and for min_samples (which influences how conservative clusters are) we minimized the number of outlier languages. We then extract the top 100 features representing those cluster-types using random forests (McInnes et al. 2017; McInnes and Healy 2017). HDBSCAN has the added advantage of automatically detecting outliers, circumventing inappropriate forcing of languages into cluster-types, and highlighting languages where kinship organization is truly irregular. Reducing our features also minimizes the amount of noise in the kinship space and makes the dataset more suitable to the dimensionality reduction technique that we use to visualize the space. Here we use the nonlinear dimensionality reduction technique UMAP (uniform manifold approximation and projection). This technique is computationally expensive but is designed to maintain the relationship between points that are far away from each other, allowing us to make inferences on the amount of change that needs to occur for systems to transform into one another (McInnes et al. 2018). Once the point clouds are represented in kinship space, we can examine the extent of variation in clusters, and compare them to the canonical typology.

\section{Interpreting the Kinship Space}

This analysis has two main outputs, cluster-types identified using HDBSCAN (Table 1), and the visualization of kinship space derived from UMAP (Fig. 5a, b). We interpret results with reference to canonical Eskimo, Hawaiian, and Sudanese systems. We introduce a combination category Cross-parallel for Omaha, Crow, Iroquoian, and Dravidian 
A

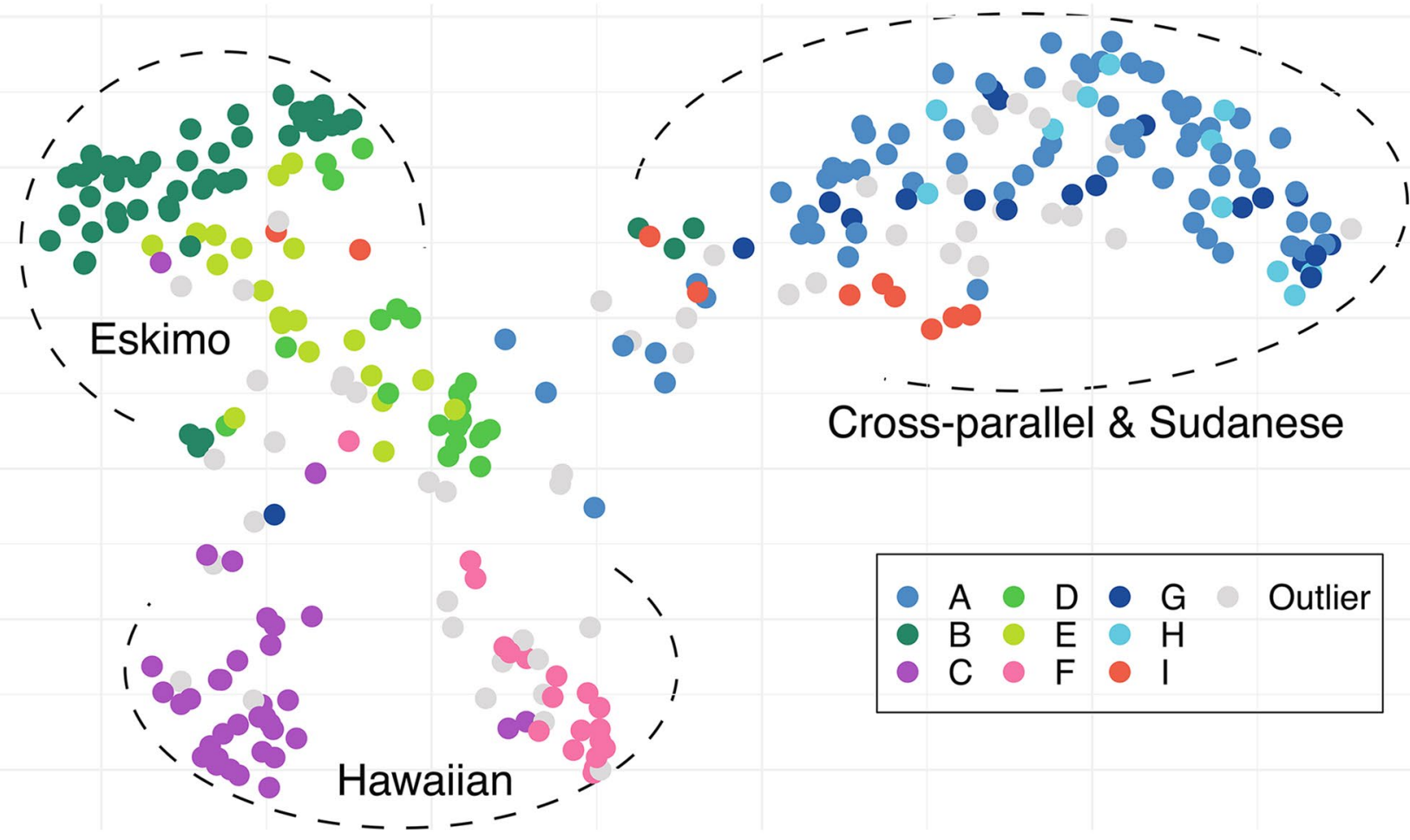

B

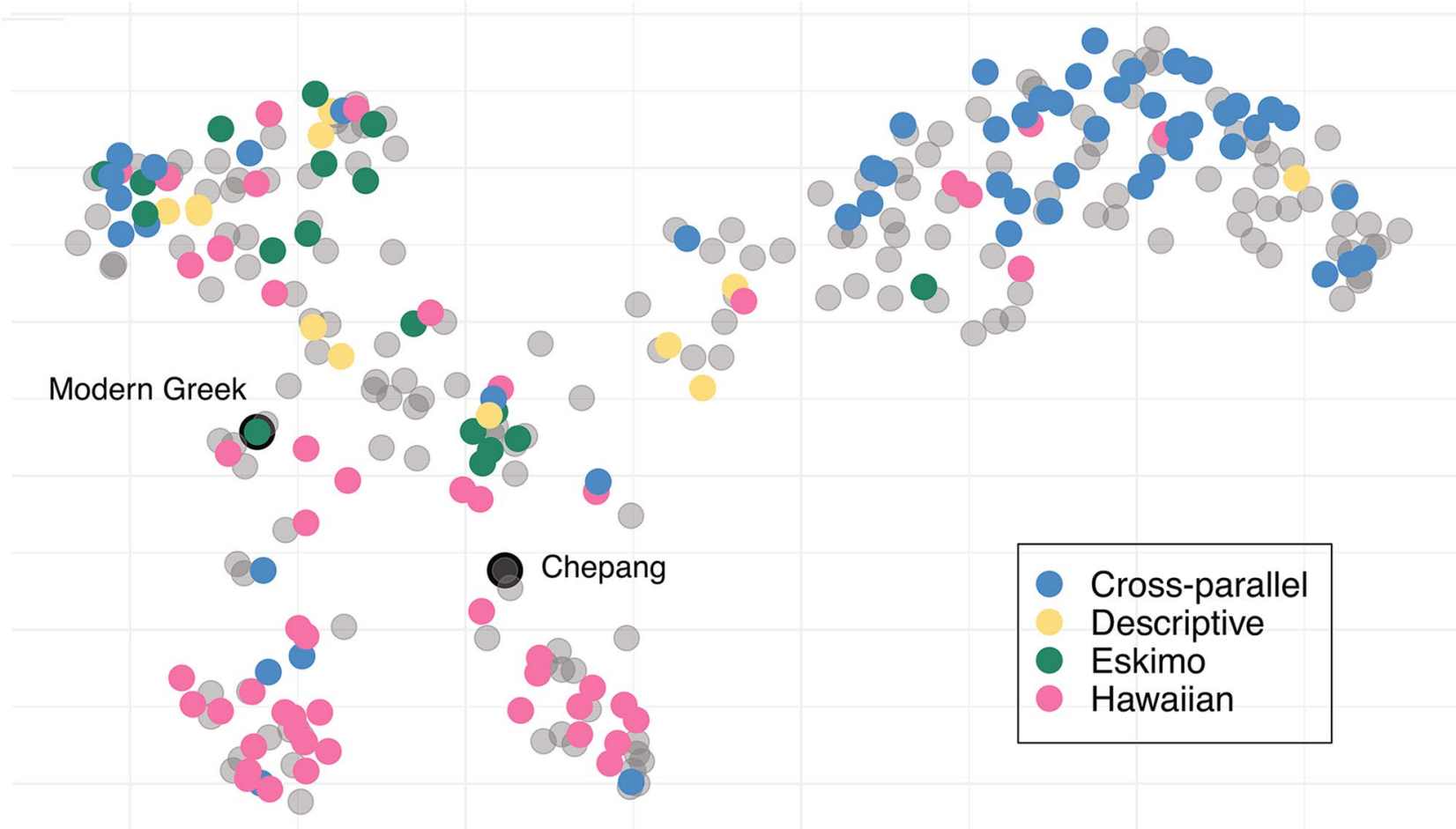

Fig. 5 a Kinship space as derived by UMAP. Each point indicates a language, and the color indicates the identified cluster using HDBSCAN (Table 1). Distance between points indicates similarity. Dashed arcs indicate the region of highest density for canonical types (“congregations"). b As for (a), except colors represent each language's canonical classification in the Ethnographic Atlas (Murdock 1967). Gray points do not have Atlas data 
systems, because they are distinguished from each other by syncretisms with $\mathrm{G}^{+1}$ terms and here we only consider $\mathrm{G}^{0}$.

\section{Cluster Identification}

HDBSCAN categorizes 255 of the 306 languages (83.3\%) into one of eight cluster-types, which map to Eskimo (3 clusters), Hawaiian (2), Cross-parallel (3), and Sudanese (1), while 51 are classified as outliers (Table 1). The data therefore display significant structure.

Structure is also seen in the UMAP representation of kinship space (Fig. 5). Not all regions are populated, and large congregations are observed. The congregations are mostly comprised of one or two cluster-types, and broadly map to the same canonical system, but there is significant fuzziness. Figure 5 shows that outliers traverse the center of the space and reach into each cluster, but notably do not lie far-flung from the main congregations. We discuss each region of space, and cluster-types within, in turn.

\section{Eskimo}

This congregation (Fig. 5a, top left and center) pulls in all three cluster-types matched to Eskimo (Table 1) but internal groups are not exclusively defined. Cluster-types B and E represent distinct sibling organizations (gender, gender and relative age), recapitulating two of the most common types found by Nerlove and Romney (1967). Gendered cousin terms (clusters D and E) are distributed towards the middle of the space, while single-cousin terms (cluster B) are tightly packed at the edge. Figure $5 \mathrm{~b}$ shows that canonical Eskimo systems in the Ethnographic Atlas (green points) overwhelmingly sit in the broad Eskimo congregation, with only one language in another region of space.

\section{Cross-parallel and Sudanese}

The common feature of this congregation (Fig. 5a, top right) is predictably the presence of crossness in various forms. The identifiable subtypes of this space are defined by relative gender (i.e., sex-of-speaker) distinctions (cluster G), relative age for siblings (cluster $\mathrm{H}$ ), and if siblings and parallel cousins receive the same term(s) (cluster A and G); Sudanese (cluster I) languages are distributed towards the center of the kinship space. Within languages comprising each identified subtype, the rules applied to siblings appear to be reliably and symmetrically applied to parallel cousins, suggesting internal co-selection: e.g., if siblings have a relative age distinction, so do parallel cousins. The cross-parallel congregation spreads over a large region, surrounded by empty space, and with only a narrow neck of contact to other congregations. While it is largely populated by canonical Crossparallel types from the Ethnographic Atlas (blue points in
Fig. 5b), all types are present, and Cross-parallel/Sudanese types are found in all other congregations. At a finer grain of analysis, we find only $42 \%$ of languages have symmetrical cross-parallel distinctions, indicating further internal variation beyond that represented here.

\section{Hawaiian}

The Hawaiian space is structured into two key subspaces, which are defined by the presence (cluster $\mathrm{C}$, bottom left of Fig. 5a) or absence (cluster F, bottom center) of relative gender rules. Hawaiian exemplars are defined by the syncretism of sibling kin terms with all cousins. Our kinship space shows this system exists, but the internal variation is significantly demarcated: these distinct types make dramatically different predictions of co-selection across generations. Figure $5 \mathrm{~b}$ shows that these categories are almost exclusively populated with languages coded in the Ethnographic Atlas as Hawaiian (blue points), but within the Atlas Hawaiian system languages are also distributed widely in all other congregations.

A number of languages sit at the central crossroads, particularly between the Eskimo and Hawaiian congregations. These languages exhibit a mix of systems, such as Chepang which has Eskimo organization in $\mathrm{G}^{0}$ relatives older than ego, but Hawaiian-styled organization for younger siblings; or their sibling and cousin terms are augmentations of each other, such as Modern Greek (Z: adelphi; FBD: exadelphi). This suggests the approach accurately represents similarity.

In sum, although the kinship space is structured, the principles driving the structure are not exceptionless, since we observe cross-parallel languages that only partially collapse parallel relatives, and Eskimo-style languages with Hawaiian-style tendencies. Rather than retaining stringent prototype-based typologies, a more fruitful approach may invoke principles that categorize kinship systems as sets of violable preferences, an idea that has previously been proposed by Jones (2010) in an optimality theoretic account. On this probabilistic view of kinship categorization, systems need not be symmetric, a problem that has long puzzled theorists (Hage 2001). While symmetric systems are observed, and often used as exemplars, many languages deviate from symmetry in order to designate terms for individuals, relationships, or groups of people that have particular cultural significance.

To return to the questions we posed. Canonical systems are significantly more variable in kinship space than a strictly coherent model would predict (Fig. 5b), and while the cluster-types derived by HDBSCAN sit neatly in congregations, none occupy exclusive positions in space. We can discern congregations, but they share a central axis where types overlap. Exploring kinship space in this manner demonstrates that the canonical systems conceal internal 
variation along axes still to be well characterized, and this is all discerned with kin term data from a single generation, $\mathrm{G}^{0}$. Our data-driven computational approach can reveal more complex variants-not by endlessly modifying prior typologies into a Copernican system, or consigning variation to mixed or transitional forms - but rather by accounting for all of the possible dimensions represented by a set of kinship terms from the bottom up. Modelling kinship space in this way, where distance maps to similarity, can also sharpen our predictions on diachronic change in kinship systems; if the central zone in Fig. 5 is a transitional hub, drilling into the system characteristics may shed light on regularities in cultural evolution.

\section{Conclusions: On the Internal Coherence of Canonical Types}

Godelier (Godelier et al. 1998, p. 392) remarked that, "there are very few kinship systems in the world. All... are variants of fewer than ten." Our analyses, using a large global dataset and new computational approaches, strongly challenge the descriptive adequacy of the limited set of canonical kinship systems. If there are "very few" systems, they are certainly not (only) those classic exemplars of Hawaiian, Dravidian, et al.; the co-selectional bonds between different parts of those systems turn out to be much weaker than assumed. Post hoc, the reasoning appears simple: classification on the basis of a small set of kin types (for example, $G^{0}$ ) gives a design space small enough that a few types engulf most ethnographic variation. Include just one more set of kin types (here, $\mathrm{G}^{+1}$ ) and both the design space and the number of types that populate it increase exponentially. This is already bad news for the canonical systems, but once we consider that our analyses only used severely pruned subsets of all possible kin terms this means that the actual patterning is likely to be substantially more complex (Passmore 2020), potentially much more than even Godelier's generous "variants of fewer than ten."

Our first analysis (in the "Testing Typological Cohesion: Clearing the Ground with New Data" section, above) showed that internal co-selection-specifically, terminological coherence between generations-is not strongly evident in the data. Correlations are only moderate, and one generation is at best mildly predictive of another. Kinship paradigms are thus less integrated than has generally been believed. Rather, diverse cultural, cognitive, and evolutionary forces will act in a dispersed way across the cells of the kinship paradigm, producing a wider range of systems than encompassed by classic typologies. But this systematicity still begs our attention because clearly, not all kinship systems are possible: changes in one part of the system do have some stochastic effect on changes in other parts, but the effects are weak enough to permit many mixed systems to evolve and persist. Recent research provides some evidence for this, showing that more distant kinterms (MB, FZ, MBD, etc.) get replaced at a faster rate than closer kinterms (M, B, Z, etc.) (Rácz et al. 2019a).

In the previous section we showed that even within a generation $\left(\mathrm{G}^{0}\right)$, diversity is much higher than canonical typologies presume. Here, we observe clustering of broad systems in kinship space (Eskimo, Hawaiian, Cross-parallel), but detect non-distinct subtypes within each of these clusters. Substantial overlap exists in the central zone of kinship space, suggesting that graded variation is a characteristic feature of kinship terminology, not a marginal source of error.

We make one important caveat for these analyses: for computational reasons we have treated languages as independent, but shared ancestry will produce some autocorrelation. Kinship terminology demonstrates reasonably high phylogenetic signal (Rácz et al. 2019a, b; Passmore and Jordan 2020) and low borrowing (Haspelmath and Tadmor 2009; Honkola and Jordan 2021), suggesting that closely related languages are likely to have the same structural organization. Nonindependence of languages means we may overrepresent some structural systems; this is most likely to affect clustering methods because frequency will determine the visibility of a subtype. We thus advise caution in making inferences (and have not done so here) about the relative importance of the kinship types we detect.

The greater empirical reach of large cultural and linguistic databases (e.g., Kirby et al. 2016), combined with computational tools that can test hypotheses and infer patterns over enormous dimensional complexity, reveal a much more heterogenous picture than the elegant typologies of 20th century anthropology gifted us. We should view this challenge positively. Kinship terminology studies fell from favor because of their abstractness from ethnographic nuance. We hope that bottom-up, data-driven approaches exploring kinship space may yet close this gap, combining the systematic semantic patterning produced by cognitive and learning constraints on the one hand, and a (hopefully tractable) handful of culturally variable and cross-cutting preferences for dimensions such as gender, age, or crossness on the other.

To advance the project, we close by suggesting two strands for further work on internal co-selection in kinship systems. First, if we are to really understand how transitions work, from one kinship type to another, we need far more careful diachronic studies than we now have. For example, as far as we can determine, there are no philological studies of the relative timing of change in $\mathrm{G}^{0}$ and $\mathrm{G}^{+1}$ terms in Latin and Old Russian (switching from Sudanese to Eskimo systems), and of when and for how long there was a period 
of typological inconsistency, i.e., a Sudanese pattern in one generation with an Eskimo pattern in the other. The question of where changes start to take place in kinship terminologies, and how they propagate throughout the system, remains underexplored.

Second, both at the level of language description, and in our own programmatic representation in our databases, we need to squarely confront the existence of variation in the denotational range of kin terms. That is, the existence of different semantic ranges for the same terms among different speakers, or even the same speaker in different contexts: it is only when we find systems exhibiting variable semantic systems that we see the smoking gun of change in progress. ${ }^{20}$ Detailed sociolinguistic and elicitation studies, and naturalistic corpora are the gold standard here, across a wide range of languages. While kinship was the earliest domain of anthropological study, we still have much to learn: armed with a realistic account of variation, we can progress.

Acknowledgments Enormous thanks to all who have contributed data and time to the Kinbank project, particularly Catherine Sheard, Joshua Birchall, and Luis Henrique Oliveira. We are grateful to the organizers and participants of the "Revisiting the Evolution of Kinship" meeting for stimulating feedback, and to Kim Sterelny for his encouragement and patience. This work was supported by the European Research Council (Starting Grant VARIKIN ERC-Stg-639291), the Leverhulme Trust (International Partnership Mobility Grant 160281), and the Australian Research Council Center of Excellence for the Dynamics of Language (Grant CE140100041).

Data Availability All data used in this project is taken from Kinbank (https://excd.org/research-activities/kinbank/). Further details on Kinbank access and availability will be available in Passmore et al. (in prep.).

Open Access This article is licensed under a Creative Commons Attribution 4.0 International License, which permits use, sharing, adaptation, distribution and reproduction in any medium or format, as long as you give appropriate credit to the original author(s) and the source, provide a link to the Creative Commons licence, and indicate if changes were made. The images or other third party material in this article are included in the article's Creative Commons licence, unless indicated otherwise in a credit line to the material. If material is not included in the article's Creative Commons licence and your intended use is not permitted by statutory regulation or exceeds the permitted use, you will need to obtain permission directly from the copyright holder. To view a copy of this licence, visit http://creativecommons.org/licenses/by/4.0/.

\footnotetext{
20 See Marley (2020) for an exemplary study showing how much variability can coexist in the kinship systems even of small languages for the Bininj Kunwok language of Northern Australia ( $<2000$ speakers) she identifies six patterns of terminology for grandparents and great-nuncles, for example.
}

\section{References}

Cronk L, Steklis D, Steklis N, van den Akker OR, Aktipis A (2019) Kin terms and fitness interdependence. Evol Hum Behav 40:281-291. https://doi.org/10.1016/j.evolhumbehav.2018.12.004

D’Andrade RG (1971) Procedures for predicting kinship terminology from features of social organisation. In: Kay P (ed) Explorations in mathematical anthropology. MIT Press, Cambridge, pp 60-75

Damerau FJ (1964) A technique for computer detection and correction of spelling errors. Commun ACM 7:171-176. https://doi.org/10. $1145 / 363958.363994$

Danziger E (1993) What might mother mean? The acquisition of kinship vocabulary in Mopan Maya. In: Clark VE (ed) Proceedings of the twenty-fifth annual child language research forum. Center for the study of language and information, Stanford, pp 227-234

Désveaux E, Selz M (1998) Dravidian nomenclature as an expression of ego-centered dualism. In: Godelier M, Trautmann TR, Tjon Sie Fat F (eds) Transformations of kinship. Smithsonian Institution Press, Washington, pp 150-167

Dole GE (1969) Generation kinship nomenclature as an adaptation to endogamy. Southwest J Anthropol 25:105-123. https://doi.org/10. 1086/soutjanth.25.2.3629197

Dole GE (1972) Developmental sequences of kinship patterns. In: Reining P (ed) Kinship studies in the Morgan centennial year. Anthropological Society of Washington, DC

Evans ND (2011) A grammar of Kayardild: with historical-comparative notes on Tangkic. De Gruyter Mouton, New York

Gardner H, McConvell P (2015) Southern anthropology: a history of Fison and Howitt's 'Kamilaroi and Kurnai.' Palgrave Macmillan, New York

Godelier M (2012) The metamorphoses of kinship. Verso Books, New York

Godelier M, Trautmann TR, Tjon Sie Fat F (eds) (1998) Transformations of kinship. Smithsonian Institution Press, Washington

Greenberg J (1966) Language universals. Mouton, The Hague

Hage P (2001) Marking theory and kinship analysis: cross-cultural and historical applications. Anthropol Theory 1:197-211. https://doi. org/10.1177/146349960100100203

Haspelmath M, Tadmor U (eds) (2009) Loanwords in the world's languages: a comparative handbook. De Gruyter Mouton, Berlin

Honkola T, Jordan F (2021) Kinship term borrowing. Paper presented at the European human behaviour \& evolution association conference, Krakow, Poland (online), 24-27 March 2021

Hughes CC (1958) An Eskimo deviant from the "Eskimo" type of social organization. Am Anthropol 60:1140-1147

Jones D (2010) Human kinship, from conceptual structure to grammar. Behav Brain Sci 33:367-381. https://doi.org/10.1017/S0140 $525 \mathrm{X} 10000890$

Kemp C, Regier T (2012) Kinship categories across languages reflect general communicative principles. Science 336:1049-1054. https://doi.org/10.1126/science.1218811

Kemp C, Xu Y, Regier T (2018) Semantic typology and efficient communication. Annu Rev Linguist 4:109-128. https://doi.org/10. 1146/annurev-linguistics-011817-045406

Kirby KR, Gray RD, Greenhill SJ, Jordan FM, Gomes-Ng S, Bibiko H-J et al (2016) D-PLACE: a global database of cultural, linguistic and environmental diversity. PLOS ONE 11:e0158391. https:// doi.org/10.1371/journal.pone.0158391

Kirchhoff P (1932) Verwandtschaftsbezeichnungen und Verwandtenheirat. Z Ethnol 64:41-72

Koerner EFK (1997) Notes on the history of the concept of language as a system 'ou tout se tient.' Linguist Atl 19:1-20

Kroeber AL (1909) Classificatory systems of relationship. J R Anthropol Inst Gt Br Irel 39:77-84. https://doi.org/10.2307/2843284 
Kronenfeld DB (2004) Definitions of cross versus parallel: Implications for a new typology (an appreciation of A. Kimball Romney). Cross-Cult Res 38:249-269. https://doi.org/10.1177/1069397104 264276

Kronenfeld DB (2006) Issues in the classification of kinship terminologies: toward a new typology. Anthropos 101:203-219

Levenshtein VI (1966) Binary codes capable of correcting deletions, insertions, and reversals. Sov Phys Dokl 10(8):707-710

Levinson SC (2006) Matrilineal clans and kin terms on Rossel Island. Anthropol Linguist 48:1-43

Lounsbury FG (1964) The structural analysis of kinship semantics. In: Hunt HG (ed) Proceedings of the ninth international congress of linguistics. Mouton, The Hague, pp 1073-1093

Lounsbury FG, Goodenough WH (1964) A formal account of the Crow-and Omaha-type kinship terminologies in explorations in cultural anthropology. In: Goodenough WH (ed) Essays in honour of George Peter Murdock. McGraw-Hill, New York, pp 351-393

Lowie RH (1928) A note on relationship terminologies. Am Anthropol 30:263-267. https://doi.org/10.1525/aa.1928.30.2.02a00060

Marley A (2020) Kundangkudjikaberrk: variation and change in Bininj Kunwok, a Gunwinyguan language of Northern Australia. PhD Thesis, Australian National University

McInnes L, Healy J (2017) Accelerated hierarchical density based clustering. In: 2017 IEEE International Conference on Data Mining Workshops (ICDMW), pp 33-42

McInnes L, Healy J, Astels S (2017) hdbscan: Hierarchical densitybased clustering. J Open Source Soft. https://doi.org/10.21105/ joss.00205

McInnes L, Healy J, Saul N, Grossberger L (2018) UMAP: uniform manifold approximation and projection. J Open Source Soft 3:861

Morgan LH (1871) Systems of consanguinity and affinity of the human family. Smithsonian Institution, Washington

Murdock GP (1949) Social structure. Macmillan Co, New York

Murdock GP (1967) Ethnographic atlas. University of Pittsburgh Press, Pittsburgh

Murdock GP (1968) Patterns of sibling terminology. Ethnology 7:1. https://doi.org/10.2307/3772805

Murdock GP (1970) Kin term patterns and their distribution. Ethnology 9:165-208. https://doi.org/10.2307/3772782

Nerlove S, Romney AK (1967) Sibling terminology and cross-sex behavior. Am Anthropol 69:179-187
Pans A (1967) Verwantschapsklassificeringen van Nieuw Guinea: Een grondslag voor de theorie-vorming over het verschijnsel verwantschapsklassifiering. Unpublished thesis, University of Amsterdam

Parkin R (1997) Kinship: an introduction to the basic concepts. WileyBlackwell, Oxford

Passmore S (2020) Quantitative approaches to kinship terminology evolution. Unpublished $\mathrm{PhD}$ Thesis, University of Bristol

Passmore S, Jordan FM (2020) No universals in the cultural evolution of kinship terminology. Evol Hum Sci. https://doi.org/10.1017/ ehs.2020.41

Rácz P, Passmore S, Sheard C, Jordan FM (2019a) Usage frequency and lexical class determine the evolution of kinship terms in IndoEuropean. R. Soc Open Sci 6:191385. https://doi.org/10.1098/ rsos. 191385

Rácz P, Passmore S, Jordan FM (2019b) Social practice and shared history, not social scale, structure cross-cultural complexity in kinship systems. Top Cognit Sci. https://doi.org/10.1111/tops.12430

Read DW (2013) A new approach to forming a typology of kinship terminology systems: from Morgan and Murdock to the present. Struct Dyn 6(1). https://escholarship.org/uc/item/0ss6j8sh. Accessed 4 Dec 2020

Romney AK, Epling PJ (1958) A simplified model of Kariera kinship. Am Anthropol 60:59-74. https://doi.org/10.1525/aa.1958.60.1. $02 \mathrm{a} 00070$

Scheffler HW (1978) Australian kin classification. Cambridge University Press, Cambridge

Stone L (2013) Kinship and gender. 4th edn. Routledge, New York

Trautmann TR (1981) Dravidian kinship. Cambridge University Press, Cambridge

Whiting JWM, Burton ML, Romney AK, Moore CC, White DR (1988) A reanalysis of Murdock's model for social structure based on optimal scaling. Behav Sci Res 22(1-4):23-40. https://doi.org/ $10.1177 / 106939718802200104$

Publisher's Note Springer Nature remains neutral with regard to jurisdictional claims in published maps and institutional affiliations. 